\title{
Urinary incontinence in women: have we anything new to offer?
}

\author{
Linda Cardozo
}

Quality of life has become a major issue for the 1990s, not only because of its social impact on the individual and society but also because of its political implications. Urinary incontinence is one of the medical conditions which severely adversely affect quality of life, and yet in the United Kingdom little attention has been focused on this problem. In the United States, however, the National Institutes of Health have acknowledged that urinary incontinence is not only abnormal and antisocial but also extremely expensive.

The conclusions of a consensus conference held at the National Institutes of Health (box 1) in 1988 are just as pertinent in the United Kingdom as in the United States, even though, numerically, the problem is smaller in the United Kingdom. Certainly, it is true that more attention is being given to this neglected disability. A recent MORI poll estimated that at least three and a half million, and possibly as many as 10 million, British people have urinary incontinence. ${ }^{2}$ Its prevalence increases with age, and it is commoner in women than men at all ages. These figures are similar to those quoted previously. In a large survey Thomas et al showed that at least a third of women aged over 35 are incontinent twice each month or more.

Before the 1970s the aetiology of urinary incontinence was poorly understood, and its classification was vague. Stress incontinence was thought to be due to

- Urinary incontinence is common among older Americans and is epidemic in nursing homes

- Urinary incontinence costs Americans more than $\$ 10$ bn/year

- Urinary incontinence is not part of normal aging, but age related changes predispose to its occurrence

- Urinary incontinence leads to stigmatisation and social isolation

- Of the 10 million Americans with urinary incontinence, more than half have had no evaluation or treatment

- Most urinary incontinence can be cured or improved

- Every person with urinary incontinence is entitled to evaluation and consideration for treatment

- Most health care professionals ignore urinary incontinence and do not provide adequate diagnosis and treatment

- Inadequate staffing of nursing homes prohibits proper treatment and contributes to neglect of residents

- Medical and nursing educations neglect urinary incontinence; development of a curriculum for urinary incontinence is urgently needed

London SE5 9RS

Linda Cardozo, MD,

consultant obstetrician and

gynaecologist

BMF 1991;303:1453-7
- Genuine stress incontinence (urethral sphincter incompetence)

- Detrusor instability (hyperreflexia)

- Retention with overflow

- Fistulae-vesicovaginal, ureterovaginal, urethrovaginal, complex

- Congenital abnormalities-for example, epispadias, ectopic ureter, spina bifida occulta

- Urethral diverticulum

- Temporary-for example, urinary tract infection, loss of mobility, faecal impaction

- Functional

BOX 2-Common causes of urinary incontinence

prolapse alone, and assessment was basically clinicako with occasional micturition cystography to evaluate theposterior urethrovesical angle. Most women in whom surgery was considered appropriate were treated with an anterior colporrhaphy. But because of its poor long term results and lack of alternatives both women anक doctors became disenchanted with the treatment, ando an unfortunate attitude of acceptance subsequently developed. Only with the advent of urodynamic studies, some 20 years ago, did the outlook for women with urinary incontinence improve considerably.

Stress incontinence is a symptom, or a sign, but not a diagnosis. It is the most common symptom of dysfunction of the lower urinary tract in women, which rarely occurs alone $e^{4}$ and may have various causes. Unfortunately, the correlation between clinical diag nosis and urodynamic diagnosis is poor, and as the treatment for the various conditions with which stress incontinence is associated is completely different it is important to ensure an accurate diagnosis. ${ }^{5}$

Box 2 shows the common causes of urinary inconti $v$ nence. About $85-90 \%$ of cases of urinary incontinence in women are due to genuine stress incontinence or detrusor instability, and as these are both commons problems it is not unusual for them to coexist.

\section{Genuine stress incontinence}

Genuine stress incontinence (urethral sphincter incompetence) is the commonest cause of urinaryo incontinence and is associated with congenital weak $\frac{\vec{D}}{\mathrm{O}}$ ness, pregnancy, vaginal deliveries, and the meno $\frac{?}{8}$ pause and may be exacerbated by previous surgery for incontinence. Women usually describe stress inconti nence with or without frequency, urgency, urge incontinence, or prolapse. Stress incontinence may be shown on clinical examination, but this only verifie the patient's history and does not diagnose the cause of the incontinence. Usually the diagnosis of genuine stress incontinence is made by exclusion. It is defined as the involuntary urethral loss of urine when the 
intravesical pressure exceeds the maximum urethral pressure without detrusor activity. Thus if cystometry shows normal findings and stress incontinence is observed the diagnosis is of genuine stress incontinence (fig 1). Videocystourethrography may help diagnosis in difficult cases.

Treatment for genuine stress incontinence may be conservative or surgical. Box 3 shows the conventional forms of treatment. Conservative treatment is indicated when the incontinence is mild, when the patient is unfit for or declines surgery, and for women who have not yet completed their families. Nowadays it may be useful when the patient is on a long hospital waiting list for surgical correction. However, it is unusual for anything more than mild genuine stress incontinence to be completely cured by these conservative measures, and most women eventually require surgery. This is unfortunate as there is an increasing demand for less interventionist treatment. A recent national survey of physiotherapeutic practice in England identified an urgent need for data on efficacy, as physiotherapists are treating many women with stress incontinence in a rather haphazard way. ${ }^{6}$ Two fairly new aids for strengthening the pelvic floor muscles, cones and maximum electrical stimulation, have been devised by Plevnik. ${ }^{78}$

Weighted vaginal cones are currently sold as a set of five, all of the same shape and size but of increasing weight (range 20-90 g). When inserted into the vagina a cone stimulates the pelvic floor to contract to prevent it from falling out and this provides "vaginal weight training." A $60 \%$ to $70 \%$ improvement rate has been reported with this technique, ${ }^{9}$ and a recent study showed that cones are as effective as more conventional pelvic floor re-educative treatment (interferential therapy) and that their use requires less supervision. ${ }^{10}$

Maximum electrical stimulation can be carried out with a home device which utilises a vaginal electrode through which a variable current is passed. The woman can adjust the strength of the stimulus and is instructed to use the device for 20 minutes daily for one month, initially. Maximum electrical stimulation has been used in managing both genuine stress incontinence and detrusor instability, and, although it is widely used in Yugoslavia ${ }^{8}$ and Scandinavia, ${ }^{11}$ it has not yet gained popularity elsewhere.

A recently reported palliative measure is the urethral plug, which in a pilot study of 14 women was effective in a proportion of those with genuine stress incontinence. ${ }^{12}$

There is no evidence that oestrogens alone are helpful in managing genuine stress incontinence, but a combination of oestrogen and the $\alpha$ adrenergic agonist phenylpropanolamine is now known to reduce urinary incontinence subjectively and objectively. ${ }^{1314}$ This

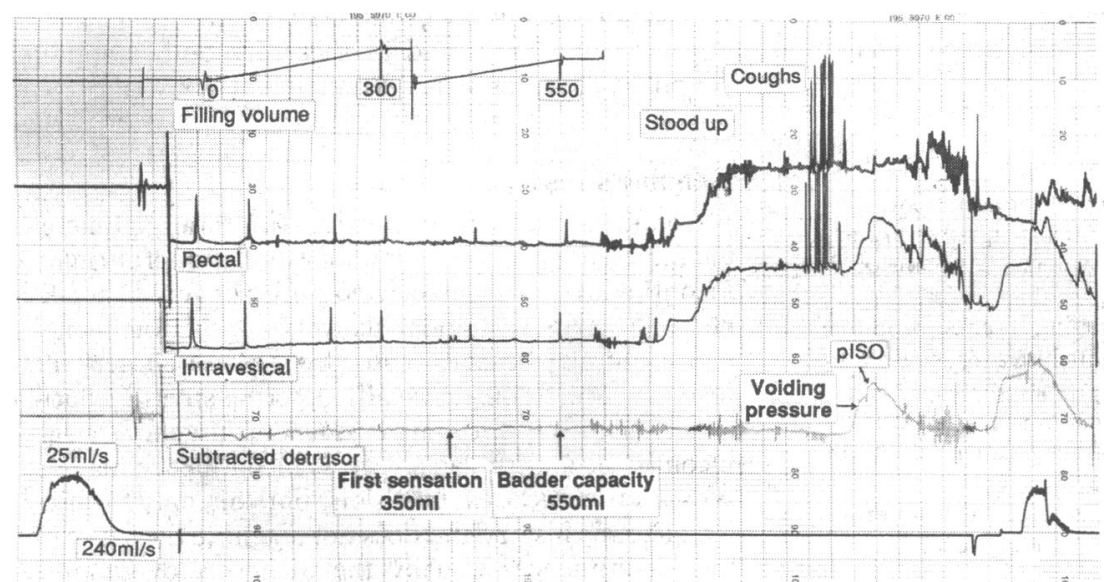

FIG 1-Normal cystometrogram from woman with genuine stress incontinence. Bottom line represents flow rate, which is normal
Conservative treatment

Kegel exercises

Faradism

Interferential therapy

Perineometry

Tampons

Mechanical devices

Oestrogens

$\alpha$ Adrenergic agonists

Surgical treatment

Vaginal -Anterior colporrhaphy

-Urethrocliesis

Abdominal - Marshall-Marchetti-Krantz operation

-Burch colposuspension

Combined - Sling

-Endoscopically guided bladder neck suspension (for example, Stamey, Raz)

Other - Neo-urethra

- Artificial sphincter

- Urinary diversion

BOX 3-Conventional treatment for genuine stress incontinence

combined treatment should be considered in managing postmenopausal women with mild genuine stress incontinence.

Surgery for genuine stress incontinence aims at elevating the bladder neck and proximal urethra to an intra-abdominal position; at supporting the bladder neck and aligning it to the posterosuperior aspect of the pubic symphysis; and, in some cases, at increasing outflow resistance. Undoubtedly, the results of suprapubic operations such as the Burch colposuspension or Marshall-Marchetti-Krantz operation are better than those for the traditional anterior colporrhaphy with bladder neck buttress, ${ }^{15}$ and a cure rate of $80-90 \%$ is generally reported. There is no "best" operation, and the procedure often needs to be tailored to suit the individual woman. The most popular operations, however, are colposuspension (retropubic urethropexy) and endoscopically guided bladder neck suspensions (for example, Stamey or Raz procedures). Colposuspension is a more major procedure with a higher incidence of side effects and complications but seems to produce a longer lasting cure for more women. ${ }^{16}$

Women who have undergone multiple previous operations and have a fixed scarred fibrosed urethra are particularly difficult to treat. Artificial sphincters have been employed, but they are expensive and still prone to mechanical problems. A new method of treatment, which is still being evaluated, is GAX-collagen (glutaraldehyde cross linked bovine collagen) treatment. The collagen is injected periurethrally on either side of the bladder neck under cystoscopic control and is intended to produce relative outflow obstruction. In the first reported series $81 \%$ of 68 women were dry after two injections ${ }^{17}$; long term follow up results are awaited

\section{Detrusor instability}

Detrusor instability is caused by uninhibited detrusor contractions which may allow the bladder pressure to exceed the urethral pressure, resulting in incontinence. The actual cause is unknown, and in most women it is idiopathic, possibly occurring as a sequel to poor bladder training in childhood or when the bladder escapes voluntary control in adult life. Emotional or other psychosomatic factors are often associated. In some women detrusor instability may be secondary to an upper motor neurone lesion such as multiple sclerosis, when it is known as detrusor hyperreflexia. An increased incidence of detrusor instability occurs after surgery for genuine stress incontinence. 


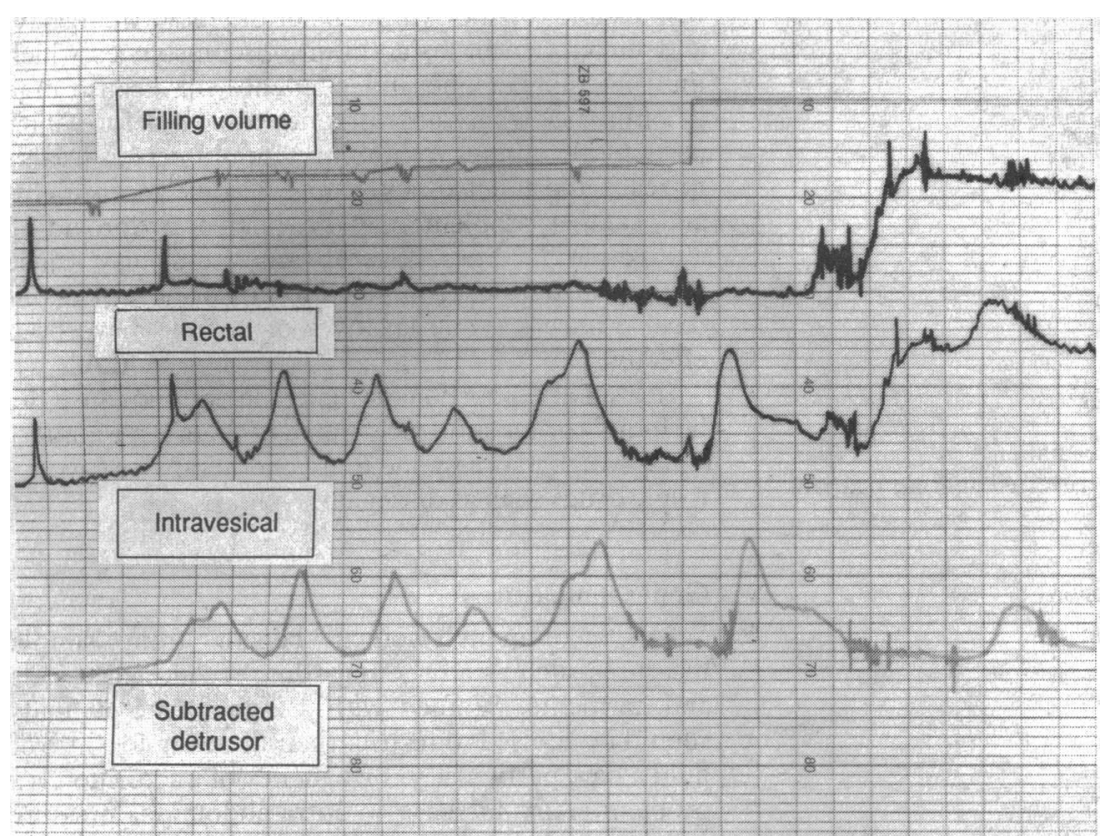

FIG 2-Subtracted

cystometrogram showing severe

phasic detrusor instability

Drug treatment for detrusor instability, according to symptoms

\begin{tabular}{ll}
\hline Treatment & \multicolumn{1}{c}{ Symptoms } \\
\hline Oxybutynin $5 \mathrm{mg}$ thrice daily & Frequency ${ }^{\star}$, urgency, urge incontinence \\
Imipramine $50 \mathrm{mg}$ at night & Nocturiat, enuresis, coital incontinence \\
Propantheline $45 \mathrm{mg}$ thrice daily & Frequency \\
Desmopressin $20 \mathrm{~g}$ at night & Nocturia ${ }^{\dagger}$, enuresis \\
${ }^{\star}>7$ times/day. $\quad \dagger \geqslant 2$ times/night:
\end{tabular}

Up to $10 \%$ of the population, may have detrusor instability, most of whom do not seek help. Most presenting women have multiple symptoms including urgency, urge incontinence, stress incontinence, enuresis, frequency, and nocturia. There are no specific clinical signs and the diagnosis depends on evidence of failure to inhibit detrusor contractions during cystometry (fig 2).

Treatment aims either at re-establishing central control or altering peripheral control through bladder innervation (box 4). Many different types of drugs have been tried previously, but none has been universally successful. Oxybutynin is the most useful drug currently available: an anticholinergic agent with a short half life, it is effective but has a high incidence of side effects. ${ }^{18}$ It is suitable for those women who do not wish to take drugs continuously and for elderly women. The incidence of its side effects may be reduced by lowering the dose from the standard $5 \mathrm{mg}$ to $3 \mathrm{mg}$ twice daily..$^{20}$ The table shows useful drugs and their commonly prescribed dosages. It is wise to

\begin{tabular}{|ll|}
\hline Psychotherapy & - Bladder drill \\
& - Biofeedback \\
& - Hypnotherapy \\
& - Acupuncture \\
Drug treatment to inhibit bladder & - Anticholinergic agents \\
contractions & - Musculotrophic relaxants \\
& - Calcium channel blockers \\
& - Tricyclic antidepressants \\
Drug treatment to increase outlet resistance & $-\alpha$ Adrenergic stimulators \\
& $-\beta$ Adrenergic blockers \\
Drug treatment affecting local tissues & - Oestrogens \\
Drug treatment to reduce urine production & - Desmopressin \\
Phenol injections & \\
Cystoplasty & - “Clam” ileocystoplasty \\
\hline
\end{tabular}

BOX 4-Treatment for detrusor instability institute anticholinergic treatment gradually to minimise side effects. Use of the synthetic vasopressin analogue desmopressin, first described nearly a decade ago, ${ }^{22} 23$ reduces nocturnal production of urine and appreciably decreases the number of night time voids in women with nocturia and occurrence of wet beds in adults with enuresis. It has been appreciated only recently, however, that many adults with nocturnals enuresis have inappropriate antidiuretic hormone. secretion; a recent study has shown that in these patients long term use of desmopressin is safe. ${ }^{24}$

In postmenopausal women adjunctive oestrogen treatment may be helpful for the symptoms of urgency, frequency, and nocturia as oestrogens are thought to $\widehat{\Phi}$ raise the sensory threshold of the bladder. ${ }^{25}$

Habit retraining in the form of bladder drill, क biofeedback, hypnotherapy, or acupuncture has been $\vec{\circ}$ successfully used to treat idiopathic detrusor instability and improves symptoms in up to $80 \%$ of women. Unfortunately, these treatments are time 0 consuming and require the patient to be highly motivated.

For those women with severe detrusor instabilityc which is not amenable to simple treatments surgery is $\infty$ required. Conventional bladder neck surgery is notụ helpful; of the various denervation procedures that $\vec{A}$ have been attempted, injection of phenol into the base of the bladder, ${ }^{26}$ which is the most recent and is stillo being used in some centres, is associated with long term poor results and a high complication rate. ${ }^{27} 28$

The "Clam" ileocystoplasty is currently the best operation for intractable detrusor instability of ${ }_{\vec{T}}^{\mathbb{D}}$ idiopathic and neuropathic origin. ${ }^{29}$ The bladder is bisected from one ureteric orifice to the other across the fundus and opened like a clam. A segment of ileumco about $25 \mathrm{~cm}$ long is isolated on its mesentery and opened along its antimesenteric border. The patch of ileum is sutured into the defect created in the bladder? to increase the size of the reservoir and thus make the uninhibited detrusor contractions ineffectual. Theo outcome in terms of continence is quite good..$^{30}$ Some patients, however, have difficulties in voiding and unacceptably high residual volumes of urine, and theyô must be prepared to catheterise themselves for the rest of their lives. In addition, copious mucus may be produced by the bowel segment, and there is a long term risk of carcinoma developing in the ileum wheres the urine impinges on it.

Women who pose a difficult management problemo are those with coexistent detrusor instability and weakness of the urethral sphincter. A recent studyo comparing medical and surgical treatments showed that of 27 women who underwent a Burch colpo-o suspension, $16(59 \%)$ were cured and six (22\%)n improved whereas of 25 women who received drug treatment, eight $(32 \%)$ were cured and seven $(28 \%)$ o improved. The authors concluded that combined stress incontinence and detrusor instability should initially be managed medically, as this will reduce the need for surgical intervention. ${ }^{31}$

\section{Overflow incontinence}

Chronic urinary retention with resultant overflowincontinence is uncommon in women and often no cause can be found. Box 5 shows the major causes. Women with overflow incontinence present in various ways. They complain of dribbling urine, or of voidinge small amounts at frequent intervals, or of stress? incontinence. Alternatively, they may notice recurrente urinary tract infections. The diagnosis is based on the observation of a large bladder on clinical examination? and may be confirmed by postmicturition ultrasonography or by catheterisation, which discloses a urinary residual volume greater than $50 \%$ of the bladder 


\begin{tabular}{|ll|}
\hline Neurological & - Lower motor neurone lesion \\
& - Upper motor neurone lesion \\
Inflammation & - Urethritis \\
& - Vulvitis \\
& - Vaginitis \\
Drugs & - Tricyclic antidepressants \\
& - Anticholinergic agents \\
& - Adrenergic stimulators \\
& - Ganglion blockers \\
& - Epidural anaesthesia \\
Obstruction & - Urethral stenosis or stricture \\
& - Oedema after surgery or parturition \\
& - Fibrosis due to repeated dilatations or irradiation \\
& - Pelvic mass (for example, fibroids, retroverted uterus, ovarian \\
& cyst, faeces) \\
Myogenic & - Urethral distortion due to large cystocele \\
Medical & - Atonic detrusor secondary to overdistension \\
& - Diabetic neuropathy \\
& - Hypothyroidism \\
Functional & - Psychosis \\
& - Anxiety
\end{tabular}

Box 5-Causes of overflow incontinence

capacity. The type of treatment depends on the underlying condition. If the detrusor is hypotonic then cholinergic agents such as bethanecol $25 \mathrm{mg}$ twice daily may be helpful or if there is outflow obstruction urethral dilatation or urethrotomy may be required. In patients with whom no cause can be found clean intermittent self catheterisation is the best long term method of management. Some women find this difficult, especially initially; a new development is the "Autocath," which helps women to insert a catheter directly into the urethra without the use of a mirror. ${ }^{32}$

\section{Other causes of incontinence}

Urinary fistulas may cause incontinence. They may be ureterovaginal, vesicovaginal, urethrovaginal, or complex and usually occur after pelvic surgery or advanced pelvic malignancy, especially that requiring radiotherapy. In developing countries poor obstetrics is more commonly to blame for fistulas of the urinary tract. Fistulas give rise to incontinence which is continuous, occurring both during the day and night and they are usually visible on examination with a speculum. Cystoscopy and intravenous urography may be required to confirm the diagnosis. Ureterovaginal fistulas should be dealt with as soon as possible to prevent damage to the upper urinary tract. Vesicovaginal fistulas are usually treated conservatively, initially with bladder drainage and antibiotics, during which time some will close spontaneously. Vaginal or abdominal repair is performed two or three months after the initial injury.

Congenital abnormalities causing incontinence are rare and are usually diagnosed at birth or in childhood. They include ectopia vesicae, epispadias, ectopic ureter, or spina bifida occulta which can cause tethering of the corda equina.

Urethral diverticula are becoming more common, presumably because of the increased incidence of sexually transmitted diseases. They are found in women of any age and lead to various complaints including pain, particularly during and after micturition, postmicturition dribble, and dyspareunia. The diagnosis is either radiological, by micturating cystography, or by urethroscopy. Urethral diverticula are often difficult to treat. Asymptomatic diverticula may be managed conservatively but those associated with severe symptoms may require surgical excision.

Urinary tract infections sometimes cause temporary incontinence which resolves with antibiotic treatment. Diuretics, especially in elderly women, may be responsible for the symptoms of urgency, frequency, and incontinence. In addition, circumstances which limit an old person's independence may cause urge incontinence where only urgency existed before. This particularly applies to mobility: an old person unable to reach the toilet quickly may become incontinent, and such a problem may be helped by providing alternative facilities. Faecal impaction may cause urinary incontinence or retention of urine which will resolve once suitable laxatives or enemas have been effective.

In a small proportion of women no organic cause can be found for incontinence. Some of them have anxiety states which may respond to psychotherapy or psychotropic drugs such as diazepam.

\section{General measures}

All incontinent women benefit from simple measures such as advice regarding incontinence pads and garments. Women with a high intake of fluids should be advised to restrict their drinking to a litre of fluid a day, particularly if frequency of micturition is a problem. Any increase in intra-abdominal pressure will aggravate incontinence: patients with a chronic cough should be advised to give up smoking, and constipation should be treated. Pelvic floor exercises may be particularly helpful in the puerperium or after pelvic surgery. Oestrogen replacement therapy for postmenopausal women is often beneficial as it improves quality of life as well as helping with some urinary symptoms. Diuretics which are often given to old people for fluid retention may exacerbate their urinary symptoms and should be stopped if possible.

Women with long standing severe incontinence, especially elderly women, may be more comfortable and easier to manage with a regularly changed indwelling urethral or suprapubic catheter, and in young disabled women urinary diversion should be considered earlier rather than later. Urinary incontinence may not always be cured, but it is usually possible to help the patient and thus improve her quality of life.

1 Urinary incontinence in adults. $\mathcal{F}$ Am Geriatr Soc 1990;38:265-72.

2 Market and Opinion Research Institute. Survey of prevalence and attitudes Market and Opinion Research Institute.

3 Thomas TM, Plymat KR, Blannin J, Meade TW. Prevalence of urinar incontinence. $B M \mathcal{F} 1980 ; 281: 1243-5$

4 Haylen BT, Sutherst JR, Frazer MI. Is the investigation of most stress incontinence really necessary? BrF Urol 1989;64:147-9.

5 Jarvis GJ, Hall S, Stamp S, Millar DR, Johnson A. An assessment of urodynamic examination in incontinent women. $\mathrm{Br} \mathcal{F}$ Obstet Gynaecol 1980;87:893-6.

6 Mantle J, Versi E. Physiotherapy for stress urinary incontinence: a national survey. BMF 1991;302:753-5.

7 Plevnik S. New methods for testing and strengthening the pelvic floor muscles. Proceedings of the 15 th Annual Meeting of the International Continence Society; 1985 Sept. London: ICS, 1985:267-8.

8 Plevnik S, Janez J, Vrtacnik P, Trasinar B, Vodusek DB. Short term electrical stimulation: home treatment for urinary incontinence. World fournal of Urology 1986:4:24-6.

9 Peatie AB, Plevnik S, Stanton SL Vaginal cones: a conservative method of treating genuine stress incontinence. Br f Obstet Gynaecol 1988;95:1049-53. 10 Olah KS, Bridges N, Denning J, Farrar D. The conservative management of patients with symptoms of stress incontinence: a randomised prospective study comparing weighted vaginal cones and interferential therapy. Am $\mathcal{F}$ Obstet Gynecol 1990;162:87-92

11 Eriksen BC, Bergmann S, Eik-Nes SH. Maximal electrostimulation of the pelvic floor in female idiopathic detrusor instability and urge incontinence. Neurology and Urodynamics 1989;8:219-30.

12 Nielsen KK, Kromannandersen B, Jacobsen H, Neilsen EM, Nordling J, Holm $\mathrm{HH}$, et al. The urethral plug - a new treatment modality for genuine stress incontinence in women. $\mathcal{F}$ Urol 1990;144:1199-202.

13 Walter S, Kjaergard B, Lose G, Andersen JT, Heisterbergn L, Jakobsen $\mathrm{H}$, ta al. Stress urinary incontinence in postmenopausal women treated with t al. Stress uninary incontinence in postmenopausal women treated with (phenylpropaniol Uro A randomised double :74, pla

14 Hilton P, Tweddell AL, Mayne C Oral and intravaginal estrogens alone and in combination with alpha adrenergic stimulation in genuine stress incontinence. International Urogynecology foumal 1990;1:80-6.

15 Stanton SL, Tanagho E. Surgery of female incontinence. 2nd ed. London: Springer Verlag, 1986

6 Bergman A, Koonings PP, Ballard CA. Primary stress incontinence and pelvic relaxation: prospective randomised comparison of three different operations. Am f Obstet Gynecol 1989;161:97-101.

17 Appell RA. New developments: injectables for urethral incompetence in women. International Urogynecology fournal 1990;1:117-9. 
18 Cardozo LD, Cooper DJ, Versi E. Oxybutynin chloride in the management of detrusor instability. Neurourology and Urodynamics 1987;6:256-7.

20 Moore $\mathrm{KH}$, Hay DM, Imrie AE, Watson A, Goldstein M Oxybutynin hydrocich hydrochloride $(3 \mathrm{mg})$ in the treatment

22 Ramsden PD, Hindmarsh JR, Price DA, Yeates WK, Bowditch JD. DDAVP for adult enuresis-a preliminary report. Brf Urol 1982;54:256-8.

23 Hilton P, Stanton SL. The use of desmopressin (DDAVP) in nocturnal urinary frequency in the female. Brf Urol 1982;54:252-

24 Knudsen UB, Rittig S, Pedersen JB, Norgaard JP, Djaarhus JC. Long term treatment of nocturnal enuresis with desmopressin-influence on urinary output and haematological parameters. Neurourology and Urodynamics 1989;8:348-9.

25 Fantl JA, Wyman JF, Anderson RL, Matt DW, Bump RC. Postmenopausa urinary incontinence: comparison between non-estrogen supplemented and estrogen supplemented women. Obstet Gynecol 1988;71:823-8.

26 Blackford W, Murray K, Stephenson TP, Mundy AR. Results of transvesical infiltration of the pelvis with phenol in 116 patients. $B r f$ Urol 1984:56: $647-9$

27 Rosenbaum TP, Shah PJR, Worth PHL. Transtrigonal phenol: the end of an era? Neurology and Urodynamics 1988;7:294-5.

28 Wall LL, Stanton S. Transvesical phenol injection of pelvic nerve plexuses in females with refractory urge incontinence. Br $\mathcal{F}$ Urol 1989;63:465-8.

29 Bramble FJ. The treatment of adult enuresis and urge incontinence by enterocystoplasty. Brf Urol 1982;54:693-6.

30 Mundy AR, Stephenson TP. "Clam" ileocystoplasty for the treatment of refractory urge incontinence. Br $\mathcal{O}$ Urol 1985;57:641-6.

31 Karam MM, Bhatia NN. Management of coexistent stress and urge incontinence. Obstet Gynecol 1989;73:4-7.

32 Rosenbaum TP. The Autocath. A new concept to facilitate self catheterization in females. Urogynaecologia 1990;IV:134.

(Accepted 15 May 1991)

\section{Medicine in Europe}

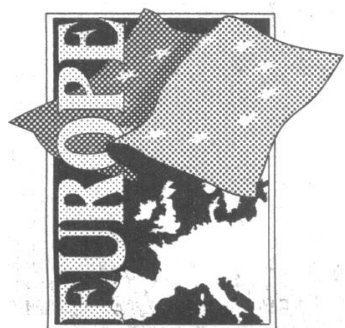

This is the third of a series of articles looking at medical issues in Europe.

\section{European health care systems}

Tony Smith

Every European country is worried about the cost of health care, and most are looking for ways of reorganising their health systems in the hope of reducing costs (see box).

In the 1970s and early 1980s expenditure on health rose faster than the growth in the economy in almost all countries in the Organisation for Economic Cooperation and Development (the OECD includes not only the countries of western Europe but also Japan, the United States, Canada, and Australia). The reasons are familiar enough. Firstly, in all these countries the proportion of old people in the population has been rising, and old people are the main consumers of health care. Secondly, technical and pharmaceutical innovations in health care have led to a real increase in demand for procedures such as joint replacement and for expensive drugs such as erythropoietin. This differential increase in health expenditure is commonly expressed as a ratio, known as the elasticity, between growth in expenditure per citizen on health and the per capita growth in the country's gross domestic product (GDP). Between 1975 and 1987 the average elasticity in OECD countries was $1 \cdot 1$-indicating that health spending was growing at a $10 \%$ faster rate than the
GDP. The elasticities ranged from 0.9 in Denmark and 1.1 in the United Kingdom to 1.3 in the United States, Belgium, and Japan. Since 1987 economic recession has led to slower growth rates in GDP and the elasticity ratio has widened. In some European countriesGermany and Sweden-expenditure on health has declined in the past three years as a proportion of GDP (see table) while in other countries it has levelled off.

\section{Basic models}

Just as every unhappy family is unhappy in its own way so each country in the OECD has evolved a unique health care system, each of which is unsatisfactory in some respects. The main division between health systems is whether they are funded primarily from taxation (as in Britain, Denmark, Italy, and Sweden) or from some form of social insurance (as in Belgium, France, Germany, the Netherlands, and Greece).

Social insurance for health was introduced in Germany under Bismarck, and in those countries which use the system enrolment in an insurance scheme is usually obligatory for all low paid workers. Usually the contributions made by workers cover

\section{Current proposals for modification to health care in European countries}

Britain is by no means alone in going through a period of rapid change in the system of health care. Most of our European neighbours are looking for ways of making their systems more efficient - or at least for ways of slowing the apparently remorseless rise in costs. Some of these proposals were discussed at a conference in Brussels in June 1991; among the talking points were the following.

France has seen spending on health accelerate far beyond the annual rise in GDP and is looking for ways of reducing its overcapacity. There is talk of cutting the number of general practitioners by 20000 and of sub stantial cuts in numbers of hospital beds. As immediate measures public hospitals have been given overall budgets with cash limits and the payments required from patients have been increased. Other proposals include a revised system of reimbursements based on the American concept of diagnosis related groups.

The Netherlands attempted in 1988 to introduce a system of regulated competition among insurance companies and among providers of health care. Individual citizens will get a subsidy to help them buy health insurance (which will remain compulsory). The subsidy will come from a central fund dependent on premiums paid by the tax collector. The competing insurance companies will offer different packages of benefits. The target date for the implementation of these proposals was originally set as 1992, but it has now been postponed to 1995.

The Germans are currently most concerned to find ways of integrating the inhabitants of eastern Germany into the existing, very expensive, health care system

In Greece there has been growing recognition of what is termed the "access trap" - the standards of care provided by many of the sickness funds are inadequate, but the private services are too expensive for most people. Greek health care for most people is based on a black economy in which patients make illegal payments to doctors to top up the doctors' inadequate salaries and reimbursement fees. This black economy is said to amount to $2 \%$ of the GDP. According to one speaker at the Brussels conference there is "a labyrinth of institutions, standards, and interests but no plans - only a lot of disillusion."

Spain is making slow progress towards introducing universal coverage through multiple financing; this will be based on a health insurance system that will require substantial contributions from employers. 